\title{
Weertman, Lliboutry and the development of sliding theory
}

\author{
A.C. FOWLER \\ MACSI, Department of Mathematics and Statistics, University of Limerick, Limerick, Republic of Ireland \\ E-mail: andrew.fowler@ul.ie
}

\begin{abstract}
This paper reviews the seminal contributions (and tussles) of Weertman and Lliboutry to the theory of glacier sliding in the 1950s and 1960s, and summarizes later developments up to the present day.
\end{abstract}

\section{THE SLIDING LAW}

Solid ice, in the form of glaciers and ice sheets, flows on long timescales, due to solid-state creep processes, and the resulting rheology is usually described in terms of a generalized Newtonian fluid. Most commonly, this takes the form of Glen's law, although other variants are possible.

The formulation of a viscous glacier flow in this way leads to an elliptic partial differential equation for the flow velocity, which requires the posing of boundary data at both the upper (free) surface and the base, or bed, of the glacier. Mostly, viscous liquids are thought to obey a noslip boundary condition at a solid boundary, on the intuitive notion that the fluid molecules effectively 'adhere' to the boundary, but there is no intrinsic reason why this should be so, and indeed the veracity of the condition was a subject of controversy in the 19th century (Goldstein, 1938). A generalization, called the Navier slip condition, allows a nonzero slip velocity proportional to stress, and it is thought that such a condition is necessary to alleviate an unphysical singularity (discontinuous velocity) which would otherwise occur in the motion of a contact line where a two-fluid interface intersects a wall (Dussan and Davis, 1974).

It has long been understood that glaciers also slip at the bed, and the resulting boundary condition for the flow which relates basal velocity, $u$, to basal stress, $\tau$, has come to be known as the sliding law, and it is the efforts that have been put into its determination that form the subject of this paper. An issue which needs immediate clarification is what is meant by the basal stress. The quantity $\tau$ refers to the shear stress in the ice near the bed (on the scale of the ice depth, $d_{i}$ ) but far from the bed (on the scale, I, of the bed roughness). In the language of matched asymptotic expansions, the basal shear stress is the limiting value at the bed of the outer solution in an asymptotic expansion in the small parameter

$$
\sigma=\frac{l}{d_{i}} \ll 1
$$

(Fowler, 1981).

\section{WEERTMAN: REGELATION AND ENHANCED CREEP}

In an early book on the dynamics of glaciers, Koechlin (1944) discusses the flow of a glacier, together with the necessary boundary condition at the base. This he takes to be that the stress exerted on the bed roughness elements should be equal to the strength of ice, and thus his basal condition is that the shear stress is constant.* The first paper in the subject which properly addresses the physics is that of Hans Weertman (1957b). In a mere six pages he enunciates the basics of the phenomena which are still considered to explain the mechanism of sliding. That glaciers slide at their base was well known (e.g. McCall, 1952; Ward, 1955); Weertman's contribution was to explicitly describe the physics of the process. This he does by quantifying two processes: regelation and 'enhanced creep'.

Regelation, otherwise known as pressure melting, is the process whereby ice can move past obstacles without deformation; as (temperate) ice approaches the upstream face of an obstacle, the pressure is higher, and therefore (because of the Clapeyron effect) the melting temperature is lower than that far away. The ice therefore melts, forming a layer of water with a thickness of the order of microns (Nye, 1967), and squirts round the obstacle to where the pressure is lower, where it refreezes, as the melting temperature is now higher. Because of the higher temperature in the lee of the obstacle, there is a compensating heat flow back through the obstacle, and it is this which delivers the latent heat necessary to melt the ice. Weertman's model of the bed is that of an array of cubical obstacles of side a separated by a distance I. Weertman's choice of notation differs from that used here. Thus the parameter

$$
\nu=\frac{a}{l}
$$

represents the aspect ratio of the bed roughness, and provides a second such parameter in addition to $\sigma$. If $\tau$ is the basal shear stress, as discussed above, then, since the lubricated bed between the obstacles offers no resistance, each obstacle bears a stress of $\sim \tau / 3 \nu^{2}$, which causes a difference of temperature of $\Delta T_{a}=C \tau / 3 \nu^{2}$ across the obstacles, where $C$ is the slope of the Clapeyron curve. ${ }^{\dagger}$

Equating the heat flow through the obstacle, $\frac{k \Delta T_{a}}{a} a^{2}$, to the latent heat flux, $\rho_{\mathrm{i}} L u_{\mathrm{R}} a^{2}$, where $k$ is thermal conductivity (of both ice and rock), $\rho_{\mathrm{i}}$ is ice density, $L$ is latent heat and $u_{R}$ is the sliding velocity due to regelation alone, he derives the regelative sliding law

$$
\tau=\nu^{2} R_{\mathrm{r}} a u_{\mathrm{R}}
$$


where the regelative roughness coefficient,

$$
R_{\mathrm{r}}=\frac{3 \rho_{\mathrm{i}} L}{k C},
$$

is a material constant. Using values $\rho_{\mathrm{i}}=0.9 \times 10^{3} \mathrm{~kg} \mathrm{~m}^{-3}$, $L=3.3 \times 10^{5} \mathrm{~J} \mathrm{~kg}^{-1}, \quad k=2 \mathrm{~W} \mathrm{~m}^{-1} \mathrm{~K}^{-1}, \quad C=0.0074 \mathrm{Kbar}^{-1}=$ $0.74 \times 10^{-7} \mathrm{~K} \mathrm{~Pa}^{-1}$, we find

$$
R_{\mathrm{r}} \approx 2 \times 10^{3} \text { bar m}^{-2} \mathrm{a}=0.63 \times 10^{16} \mathrm{~Pa} \mathrm{~m}^{-2} \mathrm{~s} .
$$

To give some idea, a driving stress of 1 bar over obstacles of elevation $1 \mathrm{~m}$ and asperity $\nu=0.2$ provides a regelative velocity of little more than a centimetre a year! Only very small obstacles or very smooth beds can support a significant regelative sliding velocity.

Next, Weertman considers the effect of differing sizes of asperities, but his argument (to this reader) is somewhat mysterious. A possible paraphrase is the following. If we suppose that an array of obstacles of asymptotically different sizes, $a_{1} \gg a_{2} \gg \cdots$ (but with the same aspect ratio, $\nu$ ) are superimposed, then we can suppose that the effects of the small-scale roughness act effectively as a surface drag to the flow past the largest-scale roughness. With a fairly obvious notation, $\tau=\nu^{2} R_{\mathrm{r}} u_{\mathrm{R}} a_{1}+\tau_{2}, \tau_{2}=\nu^{2} R_{\mathrm{r}} u_{\mathrm{R}} a_{2}+\tau_{3}$, etc., and thus

$$
\tau=\nu^{2} R_{\mathrm{r}} u_{\mathrm{R}} \sum_{i} a_{i}
$$

Consequently the largest obstacles control the rate of sliding, which for reasonable sizes will then be negligible.

Weertman next considers the viscous creep of ice past an obstacle. The differential stress past an obstacle is $\sim \tau / 2 \nu^{2}$, while the strain rate is $\sim u_{V} / a$, where $u_{V}$ is the creepcontrolled sliding velocity. Assuming Glen's law in the form $\dot{\varepsilon}=B \tau^{n}$, where $\dot{\varepsilon}$ is the strain rate and $B$ and $n$ are contants, this suggests the viscous sliding law

$$
\tau=\nu^{2} R_{\mathrm{v}}\left(\frac{u_{\mathrm{v}}}{\mathrm{a}}\right)^{1 / n}
$$

where the viscous roughness coefficient is

$$
R_{\mathrm{v}}=\frac{2}{B^{1 / n}} .
$$

Weertman used a version of Glen's law with $n=4.2$, but if we take Cuffey and Paterson's (2010) recommended value of $B=2.4 \times 10^{-24} \mathrm{~Pa}^{-3} \mathrm{~s}^{-1}$ with $n=3$, then we have

$$
R_{\mathrm{v}} \approx 1.49 \times 10^{8} \mathrm{~Pa} \mathrm{~s}^{1 / 3}=4.7 \text { bara }^{1 / 3} .
$$

Repeating our earlier estimate for $\nu=0.2$ and $a=1 \mathrm{~m}$, we find that a shear stress of 1 bar $\left(10^{5} \mathrm{~Pa}\right)$ produces a viscous sliding velocity of $150 \mathrm{~m} \mathrm{a}^{-1}$, but now (with constant $\nu$ ) the sliding velocity decreases as obstacle size is reduced. By analogy with Equation (6), a viscous sliding law for flow over a superimposed array of obstacles of sizes $a_{i}$ takes the form

$$
\tau=\nu^{2} R_{\mathrm{v}} u_{\mathrm{v}}^{1 / n} \sum_{i}\left(\frac{1}{a_{i}}\right)^{1 / n},
$$

suggesting that very small-scale roughness will prevent significant sliding.

Finally, Weertman combines the two mechanisms to produce his famous sliding law, applicable to beds with a full range of obstacle size. His argument is that for large obstacles sliding is easy by viscous creep, while for small obstacles sliding is easy by regelation. There will thus be a critical controlling obstacle size where the velocities, $u_{R}$ and
$u_{V}$, for a given a are comparable. Equating these two determines the controlling obstacle size as

$$
a_{*}=\left(\frac{\tau}{\nu^{2}}\right)^{-(n-1) / 2}\left(\frac{R_{\mathrm{r}}}{R_{\mathrm{v}}}\right)^{1 / 2},
$$

and now selecting only this obstacle size, we find Weertman's law in the form

$$
\tau=\nu^{2} R u^{2 /(n+1),}
$$

where

$$
R=\left(\frac{R_{\mathrm{v}} R_{\mathrm{r}}}{4}\right)^{1 /(n+1)} .
$$

(Weertman omitted the factor 4 because he took $u=u_{R}=$ $u_{V}$, whereas Equation (13) assumes $u=u_{R}+u_{V}$.) With $n=3$ and the values in Equations (5) and (9), we have

$$
R \approx 15.1 \text { bar m}^{-1 / 2} \mathrm{a}^{1 / 2}=0.85 \times 10^{10} \mathrm{~Pa} \mathrm{~m}^{-1 / 2} \mathrm{~s}^{1 / 2} .
$$

Taking $\tau=1$ bar $=10^{5} \mathrm{~Pa}, \nu=0.2$, we find a sliding velocity of $1.4 \mathrm{ma}^{-1}$. Given the crudeness of the model, this gives a laudable estimate of the sliding velocity. Particularly, the choice of $\nu$ is rather arbitrary, and since the sliding velocity is inversely proportional to its fourth power, higher sliding velocities are easily obtained. For example, a sliding velocity of $\sim 44 \mathrm{~m} \mathrm{a}^{-1}$ is obtained with a choice of $\nu=0.1$.

Weertman's heuristic argument can be slightly tightened in the following way. Considering the flow past obstacles of size $a$, it seems reasonable (because the regelative velocity is a plug flow) to consider the velocity to be the sum of $u_{R}$ and $u_{v}$, thus

$$
u=\frac{T}{\nu^{2} R_{\mathrm{r}} \mathrm{a}}+\left(\frac{T}{\nu^{2} R_{\mathrm{v}}}\right)^{n} \mathrm{a},
$$

which implicitly defines the stress, $T(u, a)$, past this size of obstacle. Then the total stress is, following our previous superposition argument,

$$
\tau=\sum_{i} T\left(u, a_{i}\right)
$$

We define dimensionless partial stress, velocity and obstacle size as

$$
T=\tau \theta, \quad u=\left(\frac{\tau}{\nu^{2} R}\right)^{(n+1) / 2} U, \quad a=a_{*} A ;
$$

then $\theta$ is defined by

$$
U=\frac{\theta}{A}+\theta^{n} A,
$$

and the sliding law is

$$
1=\sum_{i} \theta\left(U, A_{i}\right)
$$

It is reasonable to suppose that $\theta \sim \mathrm{O}(1)$ for some value of $A$, and in this case we must have $U \gtrsim 1$. If $U \gg 1$ then $\theta \gg 1$ for $A \sim 1$, so we must have $U \sim \mathrm{O}(1)$. Hence $\theta \ll 1$ unless $A \sim \mathrm{O}(1)$. Taking $A=1$ (i.e. the controlling obstacle size), then Equation (19) is simply $\theta(U, 1)=1$, and thus $U=2$, corresponding to Weertman's law as given above in Equation (12).

\section{Sub-temperate sliding}

In his paper, Weertman (1957b) makes the comment 'there should be no sliding in a glacier whose bottom surface is appreciably below the pressure melting point', and is thus 
seemingly aware that there will be some sliding even if the ice is a little below the melting point. If the ice is sub-cooled by an amount $\Delta T$, then two modifications to Weertman's theory are necessary. Firstly, the bed should only be lubricated by a water film at the obstacles; between them the ice will be mildly frozen to the bed. It seems possible that for small sub-coolings, the alternate frozen and lubricated parts of the bed may lead to stick-slip behaviour, as suggested by Robin (1976), and an appropriate way to describe the effect of the frozen part of the bed might be through a frictional stress of the form

$$
\tau_{\mathrm{f}}=\mu \mathrm{N},
$$

where $N$ is the overburden normal stress and the coefficient of friction, $\mu$, is a rapidly increasing function of $\Delta T$ (Barnes and others, 1971). The sliding law thus calculates the residual stress, $\tau-\tau_{\mathrm{f}}$.

The second modification arises because the heat flow through the rock must now provide not only the latent heat to melt the film on the obstacle, but also the conductive heat away from the rock into the sub-cooled ice. This modifies Equation (3) (bearing in mind also the residual stress) to

$$
\tau-\tau_{\mathrm{f}}=\nu^{2}\left(R_{\mathrm{r}} a u_{\mathrm{R}}+\frac{3 \nu \Delta T}{C}\right),
$$

while the viscous sliding law is modified to

$$
\tau-\tau_{\mathrm{f}}=\nu^{2} R_{\mathrm{v}}\left(\frac{u_{\mathrm{v}}}{\mathrm{a}}\right)^{1 / n}
$$

The experiments of Barnes and others (1971) suggest we might take

$$
\mu=\mu^{\prime} \Delta T,
$$

with a value* $\mu^{\prime} \approx 0.4 \mathrm{~K}^{-1}$, giving

$$
\tau_{\mathrm{f}}=\mu^{\prime \prime} \Delta T,
$$

where

$$
\mu^{\prime \prime}=\mu^{\prime} N
$$

a typical value is $\mu^{\prime \prime} \approx 4$ bar K$^{-1}=4 \times 10^{5} \mathrm{~Pa} \mathrm{~K}^{-1}$ for a $100 \mathrm{~m}$ deep glacier. By comparison, $3 \nu^{3} / \mathrm{C} \approx 0.4$ bar $^{-1}=$ $0.4 \times 10^{5} \mathrm{PaK}^{-1}$ for $\nu=0.1$. This suggests that we neglect the ice heating term, and in this case the controlling obstacle idea works exactly as before, yielding the sub-temperate sliding law

$$
\left[\tau-\mu^{\prime \prime} \Delta T\right]_{+}=\nu^{2} R u^{2 /(n+1)},
$$

where $[x]_{+}=\max (x, 0)$, and this gives a nonzero sliding velocity if $\Delta T<\Delta T_{\mathrm{c}}=\frac{\tau}{\mu^{\prime \prime}}$, with a typical value of $\Delta T_{\mathrm{c}} \approx 0.1 \mathrm{~K}$.

Weertman's ingenious theory has some notable features. The sliding velocity is very sensitive to the roughness, $\nu$.

\footnotetext{
*See their figure 9. In fact, they find that $\mu$ depends on ice velocity, with three regimes: (1) A low-velocity region where $\mu$ increases with ice speed. This region is associated with ice creep, presumably due to the very large shear stresses that are being experimentally applied. (2) A plateau associated with plastic flow and fracture. We associate this with the solid friction assumed here. (3) Finally $\mu$ decreases in a region assumed to be associated with the formation of a lubricating water film, corresponding in our situation to the spread of the water film between the obstacles.
}

'Lliboutry's cavitation formula is modified here for cosmetic reasons by the inclusion of the factor 2 in the denominator of the square root. Some such adjustment is necessary for arithmetic consistency, although in his 1959 paper he has an altogether different formula (Equation (30)).
Reasonable values of sliding velocity emerge if we take $\nu=0.1$. But what does reasonable mean? When a glacier slides, it seems that the sliding velocity is typically comparable to that due to shearing (table 7.3 of Cuffey and Paterson, 2010). This suggests that the roughness of the glacier bed adapts itself so that this should be the case. How could that be?

If we believe the Weertman theory at face value, then the stresses over the obstacles are of the order of $\tau / 2 \nu^{2}$, and with $\tau=1$ bar $=10^{5} \mathrm{~Pa}$ and $\nu=0.1$, this is 50 bar, or $5 \times 10^{6} \mathrm{~Pa}$ ! Ice fractures at much lower values, which suggests there is something amiss with the theory. This was pointed out by Lliboutry (1968), to whose alternative theory we now turn.

\section{LLIBOUTRY: EFFECTIVE PRESSURE AND MULTIVALUED SLIDING LAWS}

The other main early contributor to the theory of glacier sliding was Louis Lliboutry. It is probably the case that Lliboutry's interest in sliding was instigated by Weertman's paper. His first note on the subject (1958b) is concerned with the passage of a surface wave down Mer de Glace between 1891 and 1893, and he suggests that the basal friction is relatively constant at $\tau \approx 1$ bar, despite a significant change in the surface velocity, in apparent contradiction to Weertman's theory. Next (1958a) he announces a modified theory based on a 'washboard bed' consisting of transverse sinusoidal ridges (Weertman's bed is called a 'tombstone bed'). The detailed calculations behind this theory are given by Lliboutry (1959), with some slight modifications to the formulae below. Lliboutry identifies (and quantifies) three separate processes; the first two are regelative and viscous sliding, essentially similar to Weertman's description. His third process is viscous flow together with cavitation, where the ice separates from the bed in the lee of obstacles, and the stress he finds for this mode of flow decreases with ice velocity, and increases with effective pressure, $N$, equal to the overburden ice pressure minus the subglacial water pressure.

The specific forms which Lliboutry finds for the shear stress due to each of these processes (which he calls processes $\mathrm{A}, \mathrm{B}$ and $\mathrm{C}$, respectively) are for regelation,

$$
\tau_{\mathrm{R}}=\frac{1}{2} R_{\mathrm{r}} \mathrm{a} u_{\mathrm{R}}
$$

(the corresponding formula in Lliboutry (1959) has a slightly different definition of $R_{\mathrm{r}}$ ); for viscous creep,

$$
\tau_{\mathrm{V}}=\frac{\pi \sqrt{3}}{2} \nu^{1+\frac{2}{n}}\left(\frac{2 u_{\mathrm{V}}}{\mathrm{a} B}\right)^{1 / n},
$$

and for viscous creep in the presence of (strong) cavitation, ${ }^{\dagger}$

$$
\tau_{\mathrm{C}}=\frac{\pi \sqrt{3}}{2} \sqrt{\frac{a B}{2 u_{\mathrm{C}}}}\left(\frac{N}{\sqrt{3}}\right)^{1+\frac{n}{2}} .
$$

Cavitation is supposed to occur if $\tau_{\mathrm{V}}>f_{\mathrm{d}} \equiv \frac{1}{2} \nu \pi N$, which is also the value where the curves for processes $\mathrm{B}$ and $\mathrm{C}$ intersect. Lliboutry (1959) indicates that Equation (29) is erroneous, and he calculates instead

$$
\tau_{\mathrm{C}}=\left[\left(\frac{\nu}{\sqrt{3}}\right)^{n}\left(\frac{\mathrm{a} B}{4 u}\right)(\pi \mathrm{N})^{2(n+1)}\right]^{1 /(n+2)},
$$

with a corresponding slightly modified value of $f_{\mathrm{d}}$. This change does not alter the general comments below. 
Lliboutry adopts Weertman's concept of controlling obstacle size, but now there are more possibilities, since there are now three different sliding processes. As for Weertman, processes A and B could balance, leading in Lliboutry's estimate to negligible velocities, and what he calls 'static' friction; or, Lliboutry ingenuously supposes, processes B and $C$ could balance, in which the controlling obstacle size places $\tau=f_{\text {d }}$, i.e. the solid friction law

$$
\tau=\mu N,
$$

where $\mu=\frac{1}{2} \nu \pi$ (if using Equations (28) and (29)). From his calculations, the regelative controlling obstacle size is $\sim 1 \mathrm{~mm}$, while the cavitational controlling obstacle size is $\sim 1 \mathrm{~cm}, *$ and thus he suggests the solid friction-like law is more appropriate.

Lliboutry accepts Weertman's notion of the controlling obstacle size without question, but it is by no means obvious that one can do so. Weertman's argument hinged on fixing the roughness, $\nu$, and seeking the value of a where $u_{R}$ intersects $u_{V}$. Consulting Equations (27) and (28), we see this is also true for Lliboutry's formulae if $\nu$ is fixed. But then Equation (29) or (30) also provides a recipe for velocity which increases with $a$, and it is no longer obvious which, if either, of the two intersection points should provide the controlling obstacle size.

Actually, Equations (28) and (29) or (30) are not alternatives, but are simply different approximations to a purely viscous sliding law of the form:

$$
\tau_{\vee}=N f(\Lambda), \quad \Lambda=\frac{2 u}{a B N^{n}},
$$

where $f$ increases in Equation (28) to $\mu$, and then decreases in Equation (29) or (30). We can regain Lliboutry's controlling obstacle argument using the version discussed above (after Equation (15)). The controlling obstacles are those which, for fixed $u$, maximize $T(u, a)$ (or, for fixed $T$, minimize $u$ ). If we adopt Equations (27) and (32), then the function $T$ is defined by

$$
f\left[\frac{u-u_{\mathrm{R}}}{\mathrm{a} B N^{n}}\right]=\frac{T}{N^{\prime}}, \quad u_{\mathrm{R}}=\frac{2 T}{R_{\mathrm{r}} \mathrm{a}} ;
$$

evidently the maximum value of $T$ is at the maximum of $f$, so the stress is approximately

$$
\tau=\mu N,
$$

and the controlling obstacle size is determined, for given $u$, by solving

$$
u=\frac{2 \mu N}{R_{\mathrm{r}} a}+a B \Lambda_{\mathrm{m}} N^{n}
$$

where $\Lambda=\Lambda_{\mathrm{m}}$ at the maximum of $f$. This only has a solution if

$$
u>u_{\mathrm{m}}=2\left(\frac{2 \mu B \Lambda_{\mathrm{m}} N^{n+1}}{R_{\mathrm{r}}}\right)^{1 / 2},
$$

in which case, however, there are two such solutions. We might suppose that we should choose the larger, on the basis that the smaller controlling obstacles will be swamped by the cavities from the larger ones. (See also Lliboutry, 1959, fig. 2.)

However, while the principle of superposition embodied in Weertman's argument is just about believable, that in Lliboutry's is less so. Nevertheless, Lliboutry's alternative

*In Lliboutry (1958a); in Lliboutry (1959) the estimate is $21 \mathrm{~cm}$. theory provides a discussion of a number of crucial features which Weertman's does not consider. In particular, he is concerned with observations, amongst them the inference that basal shear stress is, in practice, relatively constant at $\sim 1$ bar. He focuses on the importance of cavitation, which introduces the effective pressure, $N$, into the sliding law. His final comment in his 1958 paper (Lliboutry, 1958a) addresses the interesting issue of how bed roughness evolves due to the ice sliding over it, and why the basal shear stress is always in the region of 1 bar. If it is much larger, because the bed is rougher, then the consequent stresses will cause fracturing of the bed (or of the ice), as for roches moutonnées, and the consequent hollows will be infilled by dead ice or frozen sediments. The bed thus becomes smoother, reducing the friction. Alternatively, if the friction is too low, then the shear stress must also be low and the glacier will not slide. Thus if there is significant sliding, the shear stress will adjust itself to be relatively uniform.

The first part of this argument seems reasonable, but the second is not fully formed. If the bed friction is indeed low, then with sufficient ice accumulation, force balance requires large longitudinal stresses, and these will also cause rupture. Rupture of the ice will lead to a catastrophic ice slide, such as happens on hanging glaciers (Röthlisberger, 1977; Faillettaz and others, 2008), while if the substrate fractures, this will create roughness and hence increased friction. In this way, Lliboutry's idea can be made consistent.

\section{WEERTMAN VS LLIBOUTRY}

Weertman's (1957b) and Lliboutry's (1958a) paper are both gems, full of insight and imagination. But in the following decade, these two authors bickered with one another through a number of publications, variously adapting or improving (largely in cosmetic ways) their two theories. The course of this tussle was finally charted in exasperation by Lliboutry (1968), following which the eruptive phase entered a period of dormancy, followed only by a brief reawakening at the International Glaciological Society symposium on 'Glacier beds: the ice-rock interface' (Lliboutry, 1979; Weertman, 1979).

Lliboutry's theoretical objections to Weertman's theory are plainly stated. The stresses transmitted across the obstacles are $\sim \tau / \nu^{2}$, and thus huge, for the sorts of roughness which it is necessary to invoke to get sensible velocities. Such large stresses would, in any case, cause fracture of the ice or of the bed, but would also cause ice separation in the lee of obstacles, and thus cavitation. Lliboutry's view of the consequences is portrayed in his book (Lliboutry, 1965b, fig. 16.20). While sliding was well known, hydraulic (water-filled) cavitation was apparently not; Lliboutry refers to it as 'a very plausible phenomenon'. Direct observations of air-filled subglacial cavities were well known (Carol, 1947; Haefeli, 1951; Kamb and LaChapelle, 1964; Vivian and Bocquet, 1973). Further, Weertman's theory does not have the ability to explain daily and seasonal variations in velocity. Lliboutry does not like Weertman's tombstone bed, and considers (Lliboutry, 1958a) his own washboard bed to be 'more realistic'. Later (Lliboutry, 1959) he describes Weertman's theory as 'inconsistent with [the] facts', the model is 'too schematic', and his punchline is 'it is good to have as a working tool a theory which does not conflict with numerous well-known facts'. Lliboutry was not one for the gentle comment. 
Weertman was, presumably, rightly proud of his achievement and was provoked by Lliboutry's comments to respond. This he did in a paper on surging glaciers (Weertman, 1962), where he extended his theory to allow for the effect of a distributed film of water at the bed, which partly drowns the smaller roughness elements. In passing, he finds Lliboutry's theory 'interesting' but untenable, while in an updated version of his original theory (Weertman, 1964b), he extends his own theory to allow for the drag of variable obstacle sizes, Lliboutry's cavitation and also the presence of a water 'layer' at the bed. The title of his paper suggests that he considers this newer theory to be definitive: in his view, it includes both his earlier one and Lliboutry's as special cases, with Lliboutry's applying in very limited situations, where the ice is $<10 \mathrm{~m}$ thick.

Nevertheless, Lliboutry persevered. Earlier, Kamb and LaChapelle (1964) had made direct measurements of sliding at the base of Blue Glacier in Washington State, USA, where they found regelation ice and cavitation. In comparing observation to Weertman's theory, they found quantitative discrepancy of an order of magnitude. Weertman (1964a) responded, essentially puffing various ' $\mathrm{O}(1)^{\prime}$ ' constants up or down by various factors to fit the observations; but so also did Lliboutry (1964b), claiming his theory conformed to the results of Kamb and LaChapelle, as well as other observations of sliding speed, while Weertman's did not. Then Lliboutry (1964a) provided his own explanation of surging glaciers with his own sliding theory, not quoting Weertman's (1962) similar effort, and again denigrating the Weertman theory. Next, the second volume of Lliboutry's treatise appeared (Lliboutry, 1965b), with a chapter on sliding, in which Weertman's (1964b) updated theory is not discussed or referenced. Finally, Lliboutry (1965a) wrote a popular article in which he bluntly states that Weetman's theory is incorrect, while his own constant friction theory is presented as fact.

Weertman, by this stage, had had enough. He wrote a reply (Weertman, 1966) to the New Scientist article, and then slates Lliboutry in a paper in the Journal of Glaciology (Weertman, 1967), which is devoted solely to destroying Lliboutry's theory. Weertman's tone has now changed from that of the calm patrician to a peremptoriness bordering on contempt. The editor allowed Lliboutry a sentence of response. Huffily, Lliboutry simply ignored the criticism and referred to his forthcoming paper in the journal.

Most glaciologists, if they have read any sliding theory papers at all, will have read Weertman's (1957b) paper. If they have read one of Lliboutry's, it will be that referred to above (Lliboutry, 1968). In this enormous paper, Lliboutry finally makes it to the Journal of Glaciology, and finally (courtesy of John Glen) to the English language. Weertman's paper has (at September 2010) 191 citations, while that of Lliboutry (1958a) has only six. Lliboutry's 1959 paper has 14, four by Lliboutry himself. But his 1968 paper has 132. This last barrage in the war between the French/Spanish glaciologist and the American material scientist finally sets out Lliboutry's stall for the future. It is Lliboutry's own weary review of the battle, a restatement of his theory, and, in typical fashion, a mind-numbing collection of different bits of calculations, and a variety of possible sliding laws.

*It is not just the geometry which is obvious; so also is the palaeogeology and the palaeobiology.
How did this 10 year war of words come about? There are interesting lessons for scientists here, ones which it is doubtful they will learn. Science often proceeds by entrenched battles, with progress finally being achieved by an unexpected washing away of resistance. And yet, looking back, there is still a tendency to think of these revolutions as being somehow rational. The type example is the 'plate tectonic revolution', in which distinguished geologists rejected the apparently obvious idea* that the continents had once been joined together, on (presumably) totally spurious grounds (Oreskes, 1999). And yet geophysicists routinely talk without embarrassment of the emergence of the theory of plate tectonics in the 1960s, as though Wegener had not existed. But the fact of that particular matter is that the geophysical establishment resisted the new theory for decades for what amounts to religious reasoning. It is no better or worse than Copernicus or Galileo.

Weertman vs Lliboutry is a two-man war of different dimension but similar status, in microcosm. Weertman's entirely elegant theory is a major advance. But it has drawbacks; he fails to see cavitation or fracture, and he fails to relate his elegant theory to observations, or worry about the horrendous dependence on roughness. He is, in fact, not a glaciologist, but a material scientist who cannot progress beyond his simple physical concept of the glacier bed.

Lliboutry, in contrast, has a far-reaching insight into the physical process. Apart from his focus on subglacial cavitation, he also raises the pertinent issue of how the bed adjusts its roughness, as it must do. This issue is one which yet awaits investigation, 50 years after its proposal. In this battle, he becomes the rebel outsider; he writes in French, his calculations are complicated and frequently full of schoolboy errors; his papers are not read, and his personality is combative, assertive and intolerant. In contrast, Weertman is the relaxed American with keen insight, getting to the heart of difficult problems. His sliding theory is simple, popular and, in essence, correct, just like his theories of ice-shelf motion and crevasse penetration. But he lacks the engagement with physical reality that drives Lliboutry, and he lacks the mathematical elegance that Nye and Kamb later introduce to the problem. These two antagonists fight their way into a meaningless heavyweight battle where science recedes into the background, and personality takes over.

Glaciology has always been one of the more convivial sciences, where field, experimental and theoretical approaches can meet without friction. But there are sometimes skirmishes: extrusion flow, hard beds vs soft beds, till rheology and subglacial mega-floods are but a few examples; some of them still to be worked out. The Weertman/ Lliboutry controversy was one which played itself out as the rest of the glaciological community looked on in bewilderment. The field has moved on, and the controversy of the time is now no more than a piece of scientific history.

\section{LATER DEVELOPMENTS}

Weertman's 1957 article (Weetman, 1957b) stimulated a good deal of interest in glacier sliding. Kamb and LaChapelle (1964) and Budd and others (1979) conducted laboratory experiments; Bindschadler (1983), Bentley (1987), Iken and Bindschadler (1986), Iken and Truffer (1997) and Fischer and Clarke (1997) presented field observations. In addition, a good deal of theoretical work 
was initiated, both analytic and numerical (Nye 1969, 1970; Kamb 1970; Morland 1976a,b; Fowler, 1981, 1986, 1987; Iken, 1981; Gudmundsson, 1997a,b; Schoof, 2005; Gagliardini and others, 2007a,b). Nye's early work vindicated Weertman's concept of the controlling wavelength, and his work and Kamb's motivated a temporary interest in the spectral character of bedrock roughness (e.g. Benoist, 1979). Latterly, the focus has turned to the importance of cavitation. While the role of regelation in providing the lubricating water film is assured, its importance as a cause of effective motion of ice past small protuberances has lost its importance, since Lliboutry's concept of cavitation allows such small obstacles to be drowned, effectively producing Weertman's water film (cf. Creyts and Schoof, 2009). Analytic and numerical work has vindicated Lliboutry's discovery of a double-valued sliding law for simple pseudoperiodic bed shapes, and the general consensus at present appears to favour a sliding law of the form of Equation (32), in which the friction function, $f$, either increases to a limiting friction at large $\Lambda$, or else has a mild maximum, depending on the details of the bed roughness.

\section{Soft beds}

The other main development in sliding theory came with the belated realization by desk-bound modellers that glaciers are often, or normally, underlain by the products of glacial erosion, and thus basal motion of the ice can be facilitated by deformation of the underlying till, if the ice is at the melting point and the till is water-saturated (MacClintock and Dreimanis, 1964; Boulton and others, 1974). Although apparently a very different situation, it is still feasible to postulate a sliding law of the form

$$
\tau=F(u, N),
$$

in which the function $F$ increases with both $u$ and $N$, and thus may be not unlike the hard bed sliding law. No matter what the rheology of the till, it is to be expected that increased stress leads to increased velocity (thus $\partial F / \partial u>0$ ) while increasing water pressure also facilitates flow (thus $\partial F / \partial N>0)$.

The real difficulty in assessing a possible sliding law over soft beds is in formulating a realistic till rheology. As a granular material, till has a yield stress (Kamb, 1991), and the simplest basal condition to use is then the solid friction law

$$
\tau=\mu \mathrm{N}
$$

This seems reasonable enough, but raises the question of how to describe the deformation of till with depth, where one would naturally suppose that $N$ is (hydrostatically) higher, and thus the till would be immobile, with slip occurring at the ice/till interface. This seems possible, but widespread evidence of till deformation indicates that till itself must deform, and thus the rheology of granular materials becomes an issue. An early marker was set down by Boulton and Hindmarsh (1987), who suggested the use of a power-law rheology for till of the form

$$
\dot{\varepsilon}=\frac{A \tau^{r}}{N^{s}},
$$

and this then leads to a sliding law of the form of Equation (37). While Equation (39) makes good physical sense, there is little convincing physical evidence for it. As a granular material with a yield stress, a plastic rheology is more appropriate, and this is supported by experimental work (e.g. Kamb, 1991; Tulaczyk and others, 2000), but it remains the case that the rheological deformation law needs to be prescribed, and there appears to be little coherent theory concerning this. For example, in order for a granular material to shear at all, dilation of the medium is necessary (so the particles can move round each other). This requires suction of water into the pore space, and thus generation of increased normal effective stress. This suggests that the simplest conceptual model for till deformation is already much more complicated than either a viscous or perfectly plastic material, and that, where till is concerned, there is still a great deal of theoretical work to be done concerning the sliding law.

\section{OUTLOOK}

Part of Lliboutry's motivation for his assault on Weertman's work was that it gave numerically inaccurate values for the sliding law. And presumably the subsequent striving by Nye, Kamb and others to develop the theory was aimed at improving the accuracy of the sliding law. After all, basal sliding is the key to understanding most of the interesting dynamical things that glaciers and ice sheets do. But when Charlie Bentley surveyed some of the various recipes which had been advanced in his 1987 review of ice streams, he found a range of velocities for Whillans Ice Stream (former Ice Stream B), Antarctica, from 0.6 to $\left(0.87 \times 10^{6}\right) \mathrm{m} \mathrm{a}^{-1}$; and none of them very close to the observed $443 \mathrm{~m} \mathrm{a}^{-1}$.

Why is this? Why has all the effort down the years to establish a realistic sliding law not led to improved formulae? A possible answer to this lies in the anthropocentric approach which has been taken. We walk on exposed former glacier beds, climbing over obstacles the same size as ourselves. We can visualize the problem at our scale, and the theories that have been developed deal with flow over individual bumps. The theories may be good and sophisticated, but in their application to real ice flows, they need to know details of bed geometry or till rheology, and this sort of information is simply not available.

If we think of analogous problems such as determining the frictional resistance between two solids, or the friction at the bed of a river, we would not imagine dwelling on the minutiae of the detailed deformation of the asperities, or the flow of stream water round plants and rocks. Study of these problems has been empirical; friction of solids or of rivers is measured, and empirical formulae fitted to the data.

Why has this not been done for glaciers? The obvious answer is that the difficulty of obtaining data precludes it. A season's fieldwork would be necessary to obtain a series of measurements of velocity, stress and basal water pressure on just one glacier and, even then, lateral stress variations, variability of basal water pressure both in space and time, and other such complications do not even indicate how the appropriate average values of the variables should be chosen. Bindschadler's (1983) work appears to be the only attempt to do this. The sliding law will remain in this curious data-free limbo until such time as a concerted programme can be organized to gather and integrate field data into a coherent theoretical framework. It is something that should be done.

In the discussion following Weertman's (1979) survey at the Ottawa Glacier Beds symposium, Bob Thomas rued the fact that 'the final solution ... will be incomprehensible ...', and he 'mourn[ed] the apparent demise of Weertman's original simple theory'. 
Weertman's simple theory is still often used, but it should not be. Weertman's concept was brilliant, but so was Lliboutry's elaboration of it. With maturity, Lliboutry's original contributions have come to be essentially accepted.

It is easy to forget, though, that Lliboutry's (1958a) paper contains two momentous ideas. The first, hydraulic cavitation and its consequences for a multivalued sliding law, has been shown to be essentially correct. But his other idea has received scant attention. Why is the shear stress so constant in glaciers? Weertman's answer was that it was because of the high value of the Glen exponent, a not unreasonable explanation. But Lliboutry's idea is more imaginative. To elaborate: if the bed is too rough, no sliding can occur, the ice thickness will build up, the shear stress will increase to the point that plucking occurs: the ice flow will erode the bed to smooth it. If the bed is too smooth, there will be widespread cavitation, cavities will fill with sediment, causing increased roughness.

Lliboutry's idea finds a more modern expression in the development of the instability theory of drumlin formation (Hindmarsh, 1998). Flow of ice over a flat sediment interface will, if the sediment is easily deformable (and thus has little resistance to shear), form corrugations in the bed, which serve the purpose for Lliboutry's argument: too-smooth beds will build their own roughness. The process will apply (on longer timescales) to hard beds as well; this suggests itself as the correct roughening mechanism in Lliboutry's argument.

The future development of the sliding law lies partly in connecting its dependence on $N$ into a coherent theory of subglacial drainage, but also, more challengingly, to a theory of bed evolution via erosion and sediment transport. Ultimately, ice flow, water flow and sediment flow must all be treated together. Fifty years on, the remarkable ideas of both Lliboutry and Weertman continue to bear fruit.

\section{ACKNOWLEDGEMENT}

I acknowledge the support of the Mathematics Applications Consortium for Science and Industry (www.macsi.ul.ie) funded by the Science Foundation Ireland mathematics initiative grant 06/MI/005.

\section{REFERENCES}

Barnes, P., D. Tabor and J.C.F. Walker. 1971. The friction and creep of polycrystalline ice. Proc. R. Soc. London, Ser. A, 324(1557), 127-155.

Benoist, J.P. 1979. The spectral power density and shadowing function of a glacial microrelief at the decimetre scale. J. Glaciol., 23(89), 57-66.

Bentley, C.R. 1987. Antarctic ice streams: a review. J. Geophys. Res., 92(B9), 8843-8858.

Bindschadler, R. 1983. The importance of pressurized subglacial water in separation and sliding at the glacier bed. J. Glaciol., 29(101), 3-19.

Boulton, G.S. and R.C.A. Hindmarsh. 1987. Sediment deformation beneath glaciers: rheology and geological consequences. J. Geophys. Res., 92(B9), 9059-9082.

Boulton, G.S., D.L. Dent and E.M. Morris. 1974. Subglacial shearing and crushing, and the role of water pressures in tills from south-east Iceland. Geogr. Ann., 56A(3-4), 135-145.

Budd, W.F., P.L. Keage and N.A. Blundy. 1979. Empirical studies of ice sliding. J. Glaciol., 23(89), 157-170.

Carol, H. 1947. The formation of roches moutonnées. J. Glaciol., 1(2), 57-59.
Creyts, T.T. and C.G. Schoof. 2009. Drainage through subglacial water sheet. J. Geophys. Res., 114(F4), F04008. (10.1029/ 2008JF001215.)

Cuffey, K.M. and W.S.B. Paterson. 2010. The physics of glaciers. Fourth edition. Oxford, Butterworth-Heinemann.

Dussan, E.B. and S.H. Davis. 1974. On the motion of a fluid-fluid interface along a solid surface. J. Fluid Mech., 65(1), 71-95.

Faillettaz, J., A. Pralong, M. Funk and N. Deichmann. 2008. Evidence of log-periodic oscillations and increasing icequake activity during the breaking-off of large ice masses. J. Glaciol., 54(187), 725-737.

Fischer, U.H. and G.K.C. Clarke. 1997. Stick-slip sliding behaviour at the base of a glacier. Ann. Glaciol., 24, 390-396.

Fowler, A.C. 1981. A theoretical treatment of the sliding of glaciers in the absence of cavitation. Philos. Trans. R. Soc. London, Ser. A, 298(1445), 637-681.

Fowler, A.C. 1986. A sliding law for glaciers of constant viscosity in the presence of subglacial cavitation. Proc. R. Soc. London, Ser. A, 407(1832), 147-170.

Fowler, A.C. 1987. Sliding with cavity formation. J. Glaciol., 33(115), 255-267.

Gagliardini, O., D. Cohen, P. Råback and T. Zwinger. 2007a. Correction to 'Finite-element modeling of subglacial cavities and related friction law'. J. Geophys. Res., 112(F4), F04009. (10.1029/2007JF000911.)

Gagliardini, O., D. Cohen, P. Råback and T. Zwinger. 2007b. Finiteelement modeling of subglacial cavities and related friction law. J. Geophys. Res., 112(F2), F02027. (10.1029/2006JF000576.)

Goldstein, S., ed. 1938. Modern developments in fluid mechanics. Oxford, Clarendon Press.

Gudmundsson, G.H. 1997a. Basal-flow characteristics of a linear medium sliding frictionless over small bedrock undulations. J. Glaciol., 43(143), 71-79.

Gudmundsson, G.H. 1997b. Basal-flow characteristics of a nonlinear flow sliding frictionless over strongly undulating bedrock. J. Glaciol., 43(143), 80-89.

Haefeli, R. 1951. Some observations on glacier flow. J. Glaciol., 1(9), 496-500.

Hindmarsh, R.C.A. 1998. The stability of a viscous till sheet coupled with ice flow, considered at wavelengths less than the ice thickness. J. Glaciol., 44(147), 285-292.

Iken, A. 1981. The effect of the subglacial water pressure on the sliding velocity of a glacier in an idealized numerical model. J. Glaciol., 27(97), 407-421.

Iken, A. and R.A. Bindschadler. 1986. Combined measurements of subglacial water pressure and surface velocity of Findelengletscher, Switzerland: conclusions about drainage system and sliding mechanism. J. Glaciol., 32(110), 101-119.

Iken, A. and M. Truffer. 1997. The relationship between subglacial water pressure and velocity of Findelengletscher, Switzerland, during its advance and retreat. J. Glaciol., 43(144), 328-338.

Kamb, B. 1970. Sliding motion of glaciers: theory and observation. Rev. Geophys. Space Phys., 8(4), 673-728.

Kamb, B. 1991. Rheological nonlinearity and flow instability in the deforming bed mechanism of ice stream motion. J. Geophys. Res., 96(B10), 16,585-16,595.

Kamb, B. and E. LaChapelle. 1964. Direct observation of the mechanism of glacier sliding over bedrock. J. Glaciol., 5(38), 159-172.

Koechlin, R. 1944. Les glaciers et leur mécanisme. Lausanne, F. Rouge et Cie.

Lliboutry, L. 1958a. Contribution à la théorie du frottement du glacier sur son lit. C. R. Hebd. Séances Acad. Sci., 247(3), 318320.

Lliboutry, L. 1958b. Frottement sur le lit et mouvement par saccades d'un glacier. C. R. Hebd. Séances Acad. Sci., 247(2), 228-230.

Lliboutry, L. 1959. Une théorie du frottement du glacier sur son lit. Ann. Géophys., 15(2), 250-265.

Lliboutry, L. 1964a. Nouveau calcul de la variation du point de fusion sous l'effet des contraintes et application au processus de 
fonte et regel sous-glaciaire. C. R. Acad. Sci. [Paris], 258, 1577-1579.

Lliboutry, L. 1964b. Sub-glacial 'supercavitation' as a cause of the rapid advances of glaciers. Nature, 202(4927), 77.

Lliboutry, L. 1965a. How glaciers move. New Sci., 28(473), 734-736.

Lliboutry, L. 1965b. Traité de glaciologie. Tome II: Glaciers, variations du climat, sols gelés. Paris, Masson et Cie.

Lliboutry, L. 1968. General theory of subglacial cavitation and sliding of temperate glaciers. J. Glaciol., 7(49), 21-58.

Lliboutry, L. 1979. Local friction laws for glaciers: a critical review and new openings. J. Glaciol., 23(89), 67-95.

MacClintock, P. and A. Dreimanis. 1964. Orientation of till fabric by an overriding glacier in the Saint Lawrence Valley. Am. J. Sci., 262(1), 133-142.

McCall, J.G. 1952. The internal structure of a cirque glacier. Report on studies of the englacial movements and temperatures. J. Glaciol., 2(12), 122-131.

Morland, L.W. 1976a. Glacier sliding down an inclined wavy bed. J. Glaciol., 17(77), 447-462.

Morland, L.W. 1976b. Glacier sliding down an inclined wavy bed with friction. J. Glaciol., 17(77), 463-477.

Nye, J.F. 1967. Theory of regelation. Philos. Mag., 16(144), $1249-1266$

Nye, J.F. 1969. A calculation on the sliding of ice over a wavy surface using a Newtonian viscous approximation. Proc. R. Soc. London, Ser. A, 311(1506), 445-467.

Nye, J.F. 1970. Glacier sliding without cavitation in a linear viscous approximation. Proc. R. Soc. London, Ser. A, 315(1522), 381-403.

Oreskes, N. 1999. The rejection of continental drift: theory and method in American earth science. New York, Oxford University Press.
Robin, G.de Q. 1976. Is the basal ice of a temperate glacier at the pressure melting point? J. Glaciol., 16(74), 183-196.

Röthlisberger, H. 1977. Ice avalanches. J. Glaciol., 19(81), 669-671.

Schoof, C. 2005. The effect of cavitation on glacier sliding. Proc. $R$. Soc. London, Ser. A, 461(2055), 609-627.

Tulaczyk, S.M., B. Kamb and H.F. Engelhardt. 2000. Basal mechanics of Ice Stream B, West Antarctica. I. Till mechanics. J. Geophys. Res., 105(B1), 463-481.

Vivian, R. and G. Bocquet. 1973. Subglacial cavitation phenomena under the Glacier d'Argentière, Mont Blanc, France. J. Glaciol., 12(66), 439-451.

Ward, W.H. 1955. Studies in glacier physics on the Penny Ice Cap, Baffin Island, 1953. Part IV: The flow of Highway Glacier. J. Glaciol., 2(18), 592-599.

Weertman, J. 1957a. Deformation of floating ice shelves J. Glaciol., 3(21), 38-42.

Weertman, J. 1957b. On the sliding of glaciers. J. Glaciol., 3(21), 33-38.

Weertman, J. 1962. Catastrophic glacier advances. IASH Publ. 58 (Symposium at Obergurgl 1962 - Variations of the Regime of Existing Glaciers), 31-39.

Weertman, J. 1964a. Discussion on Kamb and LaChapelle's paper 'Direct observation of the mechanism of glacier sliding over bedrock'. J. Glaciol., 5(39), 374-375. [Letter.]

Weertman, J. 1964b. The theory of glacier sliding. J. Glaciol., 5(39), 287-303.

Weertman, J. 1966. How glaciers move: a reply. New Sci., 29(481), 298.

Weertman, J. 1967. An examination of the Lliboutry theory of glacier sliding. J. Glaciol., 6(46), 489-494.

Weertman, J. 1979. The unsolved general glacier sliding problem. J. Glaciol., 23(89), 97-115. 